\title{
The effect of phase changes of water on the development of volcanic plumes
}

\author{
Michael Herzog a , Hans-F. Graf a , Christiane Textor ${ }^{\text {a }}$, Josef M. Oberhuber ${ }^{\text {b,* }}$ \\ ${ }^{a}$ Max-Planck Institute for Meteorology, Bundesstraße 55, 20146 Hamburg, Germany \\ ${ }^{\mathrm{b}}$ German Climate Computing Centre, Model Development and Application Group, Bundesstraße 55, 20146 Hamburg, Germany
}

Received 5 January 1998; accepted 6 August 1998

\begin{abstract}
A complex thermodynamic-microphysical package has been formulated that is able to deal with the microphysical processes of condensed water vapour in a volcanic plume. The microphysics follows a prognostic bulk approach for cloud water, cloud ice, rain and graupel and the interaction between them. In a standard experiment, this module, applied within a new nonhydrostatic volcano plume model, Active Tracer High Resolution Atmospheric Model (ATHAM), produces reasonable concentrations of different types of hydrometeors. Under tropical conditions, the plume gains three times as much water from the environment through entrainment as from the volcanic source. The formed hydrometeors are dominated by the ice phase. Thermodynamic effects of phase changes contribute about $13 \%$ to the plume's total thermal energy and therefore have a considerable effect on the vertical development of the plume. (C) 1998 Elsevier Science B.V. All rights reserved.
\end{abstract}

Keywords: phase change; water; volcanic plume

\section{Introduction}

The opacity of volcanic plumes is determined to a large extent by condensed water in addition to fragmented rock and lava (ash). Water vapour is one of the main components of gaseous volcanic emissions both for steady degassing and during explosive events (Coffey, 1996). Ambient atmospheric water vapour is entrained into eruption plumes by turbulent motions and is responsible for most of the water in the eruption column (Murcray et al., 1981). Microphysical processes determine the behaviour of water in the

\footnotetext{
* Corresponding author
}

plume and its effects on the plume energetics, the sedimentation of ash particles as well as the chemical transformation and the residence time of other volcanic gases. The latter processes have only been rudimentarily considered so far.

Latent heat is released when water vapour condenses or deposits. This extra energy can accelerate the plume's ascent (Woods, 1993; Glaze et al., 1997). The plume, however, can also lose energy through evaporation and melting of water and ice. Microphysical processes lead to a redistribution of energy in the plume. Energy produced by condensation and formation of small cloud droplets in higher layers is consumed by evaporation and melting of precipita- 
tion in lower levels. The atmosphere only gains net latent energy if precipitation reaches the ground.

The interaction of ash particles with solid or liquid hydrometeors initiates scavenging processes. The surface properties of ash are modified and wet ash particles can form ash clusters with a larger fall speed than the very fine initial particles (Sheridan and Wohletz, 1983; Rose et al., 1995). The processes controlling the fate of water in the volcanic plume may therefore have a strong impact on the sedimentation processes as well as on the plume development as a whole. In addition to this, volcanic gases could be extracted from volcanic plumes in the presence of water very effectively (Tabazadeh and Turco, 1993). The water solubility of the gases, mainly sulfur and chlorine species, is of interest here. The adsorption of gases on particle's surfaces also contributes to the gas extraction from the gaseous phase.

In order to treat these processes more explicitly, a module of cloud microphysics was developed for the nonhydrostatic volcano plume model, Active Tracer High Resolution Atmospheric Model (ATHAM) (Oberhuber et al., 1998). This tool treats the complete cloud microphysics, including the formation of liquid and solid precipitation and their interaction with each other. The interaction of ash particles with solid or liquid hydrometeors is neglected.

In our paper, we will firstly give a short description of ATHAM and the microphysical parameterizations, followed by a study of the influence of microphysical parameterizations on the plume development in the model.

\section{The ATHAM model}

The plume model, ATHAM, is designed to simulate explosive volcanic eruptions for a given forcing as lower boundary condition.

In the present version, ATHAM consists of four modules:

(1) The dynamic part solves the equations of motion for a gas particle mixture including the transport of active tracers.

(2) The turbulence closure scheme computes turbulent exchange coefficients for each dynamic quan- tity and describes the entrainment, i.e., mixing of ambient air into the plume.

(3) The microphysics is based on a Kessler-type parameterization. All phase transfer processes between vapour, liquid and solid as well as coagulation of hydrometeors are included.

(4) The soil model is based on a simplified version of the snow cover model of (Loth et al., 1993; Schwanke, 1995). It computes the amount of sedimented particles, ashes and water and provides a model consistent lower boundary condition for temperature and humidity. This means the atmosphere can be heated from the ground and water can evaporate into the atmosphere.

The effect of longwave radiation is included via a bulk formulation based on the Stefan Boltzmann law and leads to an increased temperature diffusion. A detailed description of solar and terrestrial radiation is not necessary since the heating or cooling rates due to radiation within the plume are several orders of magnitude smaller than those due to turbulent diffusion.

The plume model, ATHAM, is fully three-dimensionally (3d) formulated with an implicit time step scheme. The flux form of the transport equations is employed for all tracers. Because of computer restrictions, it is impossible to use the $3 \mathrm{~d}$ version as a test version. Therefore, two different types of two-dimensional $(2 \mathrm{~d})$ versions are implemented:

- One $2 d$ version computes on a vertical slice of the $3 \mathrm{~d}$ model and allows for the study of cross wind effects. The $3 \mathrm{~d}$ counterpart is a fissure eruption with infinite extent.

- The second $2 \mathrm{~d}$ version represents cylindrical coordinates. No cross wind effects can be studied, but the dilution of the mixture corresponds to the $3 \mathrm{~d}$ case.

The simulations are performed on a stretched grid with $127 \times 127$ grid points. The horizontal domain is typically $200 \mathrm{~km}$ and the vertical $50 \mathrm{~km}$. In the centre of the model domain, we use a spatial resolution of $100 \mathrm{~m}$ or less. The simulated time is typically $1 \mathrm{~h}$.

The special feature of ATHAM is its ability to treat active tracers. In contrast to passive tracers normally used in atmospheric models, active tracers can occur in any concentration and can have a strong impact on the dynamics of the system. In case of a 
volcanic eruption, the mass fraction of silicate particles close to the vent is typically higher than $90 \%$, so that they influence the dynamics of the system in two ways. Firstly, in the presence of solid or liquid particles, the density of the mixture is in general greater than the density of the gas phase alone. As a consequence, the buoyancy force can be strongly reduced. Secondly, silicate particles can act as a heat source or sink and thereby change the temperature distribution and the dynamics of the system.

Without additional assumptions, the description of a multicomponent system of active tracers requires a set of dynamic and thermodynamic equations for each component with interactions between them. This is an almost intractable problem for an arbitrary number of active tracers.

The main assumption of ATHAM is only a minor restriction in the case of a plinian eruption plume (Oberhuber et al., 1998): all particles are small. This has two consequences in physical terms:

(1) The system is in dynamic equilibrium at all times. This means we assume an instantaneous momentum exchange between particles and gas. All particles move with their terminal velocity relative to the gas phase, which allows for the description of sedimentation.

Processes on time scales in the order of a second are typical for the development of the mesoscale plume. Therefore, the time period which the particles need to reach their terminal velocity must be shorter than $1 \mathrm{~s}$. This limits the terminal velocity of particles to a few meters per second.

(2) The system is at all times in thermal equilibrium: tracers can act as a source or sink of heat, but the temperature exchange is instantaneous.

The assumption of a thermal equilibrium is not necessary within our model concept: an additional prognostic equation for particles which are not in a thermal equilibrium can easily be added. However, compared with the influence of turbulent processes and a mean horizontal wind for example, the effect of a thermal disequilibrium is of second order.

The assumption of small particles strongly reduces the number of prognostic quantities and allows for the treatment of a multi-component system with any number of active tracers. The dynamic behaviour of the gas particle mixture is described by five prognostic equations for the three momentum com- ponents, the pressure and the temperature. For each tracer, one additional transport equation is taken into account. Apart from two types of silicate particles (ash and lapilli), five types of tracers for the microphysics are implemented in the present version: water vapour, cloud water, precipitable water, cloud ice and graupel. Active tracers and dynamic variables are coupled by the bulk density and the heat capacity of the mixture.

\section{Fall velocities}

In our model concept, fall velocities are only relevant for raindrops, graupel, ash particles and lapilli since cloud droplets and ice are, by definition, suspended in the air.

For very small particles with radii less than 35 $\mu \mathrm{m}$, the interaction between gas and particles can be described by Stokes friction for which the friction force is proportional to the relative particle velocity. Then the stationary fall velocity $w_{1}$ is proportional to the square of the particle radius $r_{\mathrm{p}}$ (Rogers and Yau, 1989). The increase of $w_{1}$ with decreasing gas density is a function of the free path length $L$ after Cunningham (Linke and Baur, 1970):

$w_{1}=\frac{2}{9} \frac{\rho_{\mathrm{p}} g}{\eta} r_{\mathrm{p}}^{2}\left(1+\frac{L}{r_{\mathrm{p}}}\left(0.864+0.29 e^{-1.25 \frac{r_{\mathrm{p}}}{L}}\right)\right)$,

where $\rho_{\mathrm{p}}$ is the particle density, $\eta$ the dynamic viscosity of the gas and $g$ the gravitational constant. The free path length is interpolated from the USstandard atmosphere (Weast et al., 1984).

Large particles $\left(r_{\mathrm{p}}>500 \mu \mathrm{m}\right)$ are influenced by Newtonian friction which is proportional to the square of the particle velocity. Then the stationary fall velocity is proportional to the square root of the radius of the particle (Rogers and Yau, 1989):

$w_{3}=\sqrt{\frac{8}{3} \frac{\rho_{\mathrm{p}} g}{C_{\mathrm{D}} \rho_{g}}} \sqrt{r_{\mathrm{p}}}$,

where $\rho_{\mathrm{g}}$ is the gas density. The drag coefficient $C_{\mathrm{D}}$ is a constant depending on the surface roughness of the particle. Gunn and Kinzer (1949) give for water 
droplets $C_{\mathrm{D}}=0.54$, for graupel we use $C_{\mathrm{D}}=0.6$ (Wisner et al., 1972), and Carey and Sparks (1986) proposed for ash particles $C_{\mathrm{D}}=0.75$.

For particles with radii between $50 \mu \mathrm{m}$ and 500 $\mu \mathrm{m}$, the fall velocity increases approximately linearly with the radius (Rogers and Yau, 1989):

$w_{2}=k_{2} \rho_{\mathrm{p}} \sqrt{\frac{\rho_{0}}{\rho_{\mathrm{g}}}} r_{\mathrm{p}}$,

with $\rho_{0}=1.12 \mathrm{~kg} \mathrm{~m}^{-3}$ as the reference gas density and $k_{2}=8 \mathrm{~m}^{3} \mathrm{~kg}^{-1} \mathrm{~s}^{-1}$.

In the model, we can use the minimum condition for the particle terminal fall velocity $w_{\mathrm{p}}=\operatorname{Min}\left(w_{1}\right.$, $\left.w_{2}, w_{3}\right)$. The values change depending on density, size and drag coefficient. In the microphysical processes involving rain and graupel, only Eq. (2) is applied, since these processes are dominated by large particles.

\section{Microphysics}

The complete description of all microphysical processes in a volcanic eruption plume is rather complex. Silicate particles as well as volcanic gases should be included: water vapour can condense or can deposit on ash surfaces. Silicate particles can interact with hydrometeors and form clusters with increased fall speed compared with that of the constituents. Volcanic gases like $\mathrm{HCl}$ can be dissolved into liquid droplets and thereby substantially lower the freezing temperature.

Since there is no observational data available concerning the microphysical processes in the plume and only very little is known about the importance of their single and combined effects for the plume development, we use a rather simple microphysical package in the first step. The interaction between water and silicate particles is ignored as well as the impact of volcanic gases. Our aim is to describe the phase transfer processes between water vapour, liquid water and ice and to estimate their influence on the plume's energy budget.

The parameterization of microphysical processes (Fig. 1) is based on Rutledge and Hobbs (1983), Lin et al. (1983), Wisner et al. (1972) and Kessler (1969)

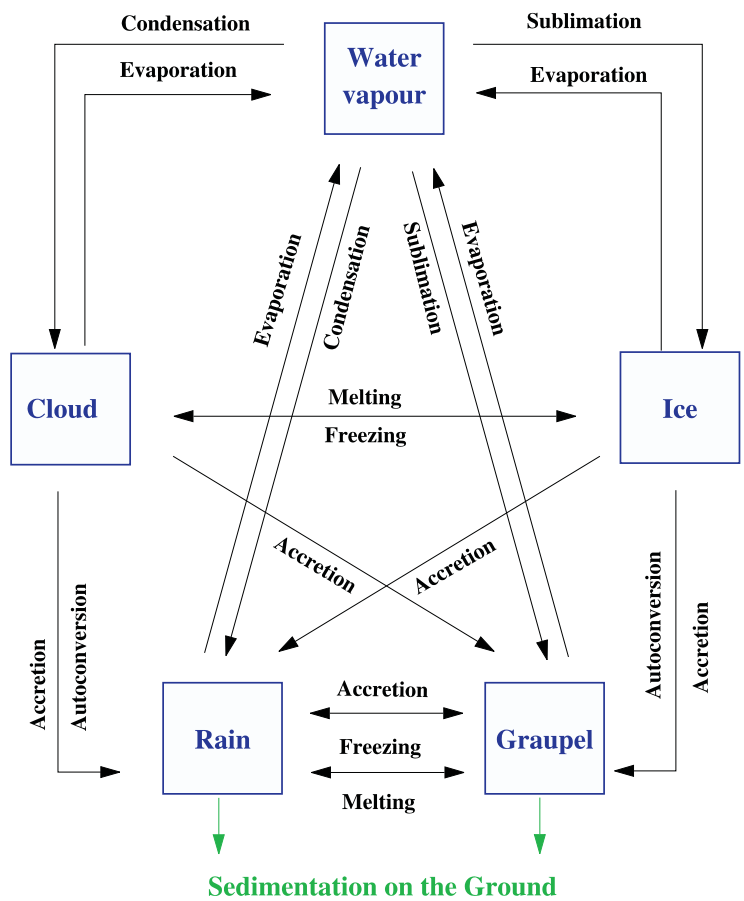

Fig. 1. Scheme of the microphysics for water.

and follows a bulk concept: all processes are determined by the mass concentration of hydrometeors per unit volume.

(1) Cloud droplets and cloud ice crystals are assumed to be monodisperse and have by definition a negligible fall velocity relative to the gas phase.

(2) Rain is formed by autoconversion of cloud droplets and interacts with all other forms of hydrometeors. Water vapour can condense on the surfaces of raindrops or be released by evaporation. Raindrops are assumed to follow a Marshall-Palmer distribution. Their mean radius determines the fall velocity of rain.

(3) For the solid phase, only one type of precipitation is included. We do not distinguish between hail, snow and other aggregates. This would only be sensible for a more complex approach to the microphysics which would include the interaction of silicate particles and hydrometeors in a volcanic eruption cloud. Instead, we use one reservoir which we call graupel. Graupel with a mean density of $700 \mathrm{~kg}$ $\mathrm{m}^{-3}$ has properties between snow and hail. The size distribution of graupel is of the Marshall-Palmer 
type where the mean radius determines the fall velocity. The formation of graupel and the interactions between graupel and other hydrometeors or water vapour are defined in an way analogous to rain. Transition between graupel and rain takes place through melting or freezing.

\subsection{Condensation and evaporation}

Condensation and evaporation processes take place at pre-existing hydrometeors. The formation of new particles is an additional process which requires condensation nuclei. These are generally abundant in the troposphere and therefore only small supersaturations of vapour are observed in cloud free areas. Inside clouds, supersaturation is practically absent. The number of condensation nuclei determines only the number of newly formed droplets. As mentioned above in our framework, we prescribe a fixed cloud drop radius. We assume that within one time step $\delta t$, the supersaturated water vapour is transformed into cloud water:

$$
\begin{aligned}
\operatorname{Con} N & =\frac{q_{\mathrm{v}}-q_{\mathrm{sat}}}{\Delta t} \text { for } q_{\mathrm{v}}>q_{\mathrm{sat}} \\
\frac{\partial}{\partial t} q_{\mathrm{c}} & =+\operatorname{Con} N \\
\frac{\partial}{\partial t} q_{\mathrm{v}} & =-\operatorname{Con} N .
\end{aligned}
$$

Mass exchange of water droplets due to condensation or evaporation can be expressed by:

$$
\frac{\partial}{\partial t} m_{\mathrm{w}}=4 \pi r C_{\mathrm{v}}\left(\frac{S_{\mathrm{w}}-1}{F_{k}+F_{\mathrm{d}}}\right),
$$

with $F_{k}$ the heat conduction and $F_{\mathrm{d}}$ the water vapour diffusion (Byers, 1965). $m_{\mathrm{w}}$ is the mass of the droplet with radius $r . C_{\mathrm{v}}$ is the ventilation coefficient depending on the Reynolds number and describing the effect of turbulence caused by the circulation around the falling droplet. $S_{\mathrm{w}}=q_{\mathrm{v}} / q_{\mathrm{sat}}$, where $q_{\mathrm{v}}$ is the specific concentration of water vapour, and $q_{\text {sat }}$ is the water vapour concentration at the saturation limit.

Solution and curvature effects on droplet's equilibrium vapour pressure are neglected: curvature effects are important only for droplets smaller than 1 $\mu \mathrm{m}$ which are not resolved through our parameteri- zations. The dissolution of volcanic gases into droplets can influence the condensation on, or evaporation of water droplets and needs to be considered in the future.

The effect of heat conduction $F_{k}$ is given by:

$F_{k}=\left(\frac{L_{\mathrm{v}}}{R_{\mathrm{v}} T}-1\right) \frac{L_{\mathrm{v}}}{K_{\mathrm{a}} T}$,

where $L_{\mathrm{v}}$ is the evaporation enthalpy, $R_{\mathrm{v}}$ the specific gas constant for water vapour, $K_{\mathrm{a}}$ the thermal conductivity of air and $T$ the in situ temperature. Finally, $F_{\mathrm{d}}$ is the contribution of water vapour diffusion,

$F_{\mathrm{d}}=\frac{R_{\mathrm{v}} T}{P_{\mathrm{sat}} D_{\mathrm{v}}}$,

where $P_{\text {sat }}$ is the saturation vapour pressure over water and $D_{\mathrm{v}}$ the diffusion coefficient for water vapour in air.

Since cloud droplets are assumed to be monodisperse and their ventilation coefficient is one, due to the zero fall velocity, we get for the condensation and evaporation of cloud droplets:

$$
\begin{aligned}
\operatorname{Con} C & =4 \pi \frac{q_{\mathrm{g}}}{\rho_{\mathrm{g}}} N_{\mathrm{c}} r_{\mathrm{c}} \frac{S_{\mathrm{w}}-1}{F_{k}+F_{\mathrm{d}}} \\
\frac{\partial}{\partial t} q_{\mathrm{c}} & =+\operatorname{Con} C \\
\frac{\partial}{\partial t} q_{\mathrm{v}} & =-\operatorname{Con} C,
\end{aligned}
$$

where $q_{\mathrm{c}}$ is the specific cloud water concentration, $q_{\mathrm{g}}$ the gas concentration including the water vapour $q_{\mathrm{v}}, \rho_{\mathrm{g}}$ the gas density, $N_{\mathrm{c}}$ the number of cloud droplets per gas volume and $r_{\mathrm{c}}$ the cloud droplet radius with a median value of $r_{\mathrm{c}}=10 \mu \mathrm{m}$.

Raindrops follow a Marshall-Palmer size distribution (Marshall and Palmer, 1948), for which the droplet number per gas volume $N_{\mathrm{r}}(r)$ in a radius interval $\mathrm{d} r$ holds:

$N_{\mathrm{r}}\left(r_{\mathrm{r}}\right) \mathrm{d} r_{\mathrm{r}}=N_{0, \mathrm{r}} e^{-2 \lambda_{\mathrm{r}} r_{\mathrm{r}}} \mathrm{d} r_{\mathrm{r}}$

with $\lambda_{\mathrm{r}}=\left(\pi \frac{q_{\mathrm{g}} \rho_{\mathrm{w}}}{\rho_{\mathrm{g}} q_{\mathrm{r}}} N_{0, \mathrm{r}}\right)^{1 / 4}$ and $N_{0, \mathrm{r}}=10^{7} \mathrm{~m}^{-4}$. 
$\rho_{\mathrm{w}}$ is the water density and $q_{\mathrm{r}}$ the specific rain water concentration (Wisner et al., 1972).

The ventilation coefficient for raindrops is (Wisner et al., 1972):

$C_{\mathrm{v}, \mathrm{r}}=1+0.22 R e_{\mathrm{r}}^{1 / 2}$

with $R e_{\mathrm{r}}=\frac{2 w_{\mathrm{r}} r_{\mathrm{r}}}{\nu}$ and $w_{\mathrm{r}}=a_{\mathrm{r}} \sqrt{r_{\mathrm{r}} \frac{\rho_{0}}{\rho_{g}}}$.

Here, $r_{\mathrm{r}}$ is the radius, $w_{\mathrm{r}}$ the fall velocity of the raindrops, and $\nu$ is the kinematic viscosity of air. Following Eq. (2), we get $a_{\mathrm{r}}=201 \sqrt{\mathrm{m} \mathrm{s}}{ }^{-1}$. Integration over the size distribution of the raindrops given in Eq. (5) yields for condensation or evaporation of raindrops:

$$
\begin{aligned}
& \operatorname{Con} R=2 \pi \frac{q_{\mathrm{g}}}{\rho_{\mathrm{g}}} N_{0, \mathrm{r}} \frac{S_{\mathrm{w}}-1}{F_{k}+F_{\mathrm{d}}} \\
& \quad \times\left(\lambda_{\mathrm{r}}^{-2}+0.22 \Gamma(2.75) \sqrt{\frac{a_{\mathrm{r}}}{\nu}}\left(\frac{\rho_{0}}{\rho_{\mathrm{g}}}\right)^{1 / 4} \lambda_{\mathrm{r}}^{-2.75}\right)
\end{aligned}
$$

$$
\frac{\partial}{\partial t} q_{\mathrm{r}}=+\operatorname{Con} R
$$

$$
\frac{\partial}{\partial t} q_{\mathrm{v}}=-\operatorname{Con} R
$$

$\Gamma(x)$ denotes the complete Gamma function of $x$.

Condensation and evaporation can also occur from melting graupel. In contrast to cloud ice, graupel can exist above the melting temperature for longer times. Since graupel is coated by a thin film of liquid water under this condition, the transition to the gas phase is by evaporation and not by sublimation. Then in Eq. (8), only the corresponding size distribution, ventilation coefficient and fall velocity have to be applied. Federer and Waldvogel (1975) observed the size distribution of frozen hydrometeors, which we shall, for simplicity, also apply for graupel here:

$$
\begin{aligned}
& N_{\mathrm{h}}\left(r_{\mathrm{h}}\right) \mathrm{d} r_{\mathrm{h}}=N_{0, \mathrm{~h}} e^{-2 \lambda_{\mathrm{h}} r_{\mathrm{h}} \mathrm{d} r_{\mathrm{h}}} \\
& \text { with } \lambda_{\mathrm{h}}=\left(\frac{q_{\mathrm{g}} \rho_{\mathrm{h}}}{\rho_{\mathrm{g}} q_{\mathrm{h}}} N_{0, \mathrm{~h}}\right)^{1 / 4} \\
& \text { and } N_{0, \mathrm{~h}}=1.21 \cdot 10^{4} \mathrm{~m}^{-4},
\end{aligned}
$$

$\rho_{\mathrm{h}}$ is the graupel density, $q_{\mathrm{h}}$ the specific concentration of graupel. The respective ventilation coefficient again follows Wisner et al. (1972):

$$
C_{\mathrm{v}, \mathrm{h}}=1.6+0.3 R e_{\mathrm{h}}^{1 / 2}
$$

with $\operatorname{Re}_{\mathrm{h}}=\frac{2 w_{\mathrm{h}} r_{\mathrm{h}}}{\nu}$ and $w_{\mathrm{h}}=a_{\mathrm{h}} \sqrt{r_{\mathrm{h}} \frac{\rho_{0}}{\rho_{\mathrm{g}}}}$,

$r_{\mathrm{h}}$ is the radius, $w_{\mathrm{h}}$ the fall velocity of the graupel particles, and according to Eq. (2) $a_{\mathrm{h}}=174.7$

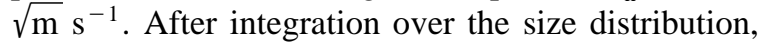
Eq. (5) gives for condensation and evaporation of melting graupel:

$$
\begin{aligned}
& \text { Con } H=2 \pi \frac{q_{\mathrm{g}}}{\rho_{\mathrm{g}}} N_{0, \mathrm{~h}} \frac{S_{w-1}}{F_{k}+F_{\mathrm{d}}} \\
& \times\left(1.6 \lambda_{\mathrm{h}}^{-2}+0.3 \Gamma(2.75) \sqrt{\frac{a_{\mathrm{h}}}{\nu}}\left(\frac{\rho_{0}}{\rho_{\mathrm{g}}}\right)^{1 / 4} \lambda_{\mathrm{h}}^{-2.75}\right) \\
& \frac{\partial}{\partial t} q_{\mathrm{h}}=+\operatorname{Con} H \\
& \frac{\partial}{\partial t} q_{\mathrm{v}}=-\operatorname{Con} H .
\end{aligned}
$$

\subsection{Sublimation and deposition}

The transformation from ice to water vapour and vice versa is only possible at temperatures below the freezing point $T_{0}$. Above this temperature, we assume that there is no more cloud ice and that all the graupel is coated by a water layer.

New cloud ice particles can be formed from the gas phase. This process is limited by the number of ice nuclei. The number of cloud ice nuclei is temperature-dependent and can be described at normal atmospheric conditions (Fletcher, 1962):

$N_{\mathrm{f}}=N_{0, \mathrm{f}} e^{\beta\left(T_{0}-T\right)}$

with $\beta=0.6 \mathrm{~K}^{-1}$ and $N_{0, \mathrm{f}}=10^{-2} \mathrm{~m}^{-3}$.

We assume that at least this number of ice nuclei exists. Together with the mass of a single cloud ice particle $m_{\mathrm{i}}$, we yield for the new formation of cloud 
ice particles (Stephens, 1979; Rutledge and Hobbs, 1983):

$\operatorname{Sub} N=\frac{q_{\mathrm{g}}}{\rho_{\mathrm{g}}} \frac{m_{\mathrm{i}} N_{\mathrm{f}}}{\Delta t}$ with $m_{\mathrm{i}}=10^{-12} \mathrm{~kg}$

$$
\begin{aligned}
& \frac{\partial}{\partial t} q_{\mathrm{i}}=+\operatorname{Sub} N \\
& \frac{\partial}{\partial t} q_{\mathrm{v}}=-\operatorname{Sub} N
\end{aligned}
$$

Because of the temperature dependence, this process is only effective at temperatures well below the freezing point.

The mass exchange of an existent ice particle by sublimation or deposition has formally the same expression as condensation and evaporation of a water droplet in Eq. (5):

$$
\begin{aligned}
& \frac{\partial}{\partial t} m_{\mathrm{s}}=4 \pi C_{\mathrm{v}} \frac{S_{\mathrm{i}}-1}{F_{k}^{\prime}+F_{\mathrm{d}}^{\prime}} \\
& S_{\mathrm{i}}=\frac{q_{\mathrm{v}}}{q_{\mathrm{sat}}^{\prime}} \\
& F_{k}^{\prime}=\left(\frac{L_{\mathrm{s}}}{R_{\mathrm{v}} T}-1\right) \frac{L_{\mathrm{s}}}{K_{\mathrm{a}} T} \\
& F_{\mathrm{d}}^{\prime}=\frac{R_{\mathrm{v}} T}{P_{\mathrm{sat}}^{\prime} D_{\mathrm{v}}} .
\end{aligned}
$$

Instead of the values for liquid water, the saturation mixing ratio over ice $S_{\mathrm{i}}$ has to be applied, where $q_{\text {sat }}^{\prime}$ is the water concentration at the saturation limit for ice. The evaporation enthalpy $L_{\mathrm{v}}$ is replaced by the sublimation enthalpy $L_{\mathrm{s}}$, and the saturation water pressure over water $P_{\text {sat }}$ is substituted by $P_{\text {sat }}^{\prime}$, the saturation water pressure over ice.

For our monodisperse ice crystals with a median radius of $r_{\mathrm{i}}=10 \mu \mathrm{m}$, we get for sublimation and deposition:

$$
\begin{aligned}
\operatorname{Sub} I & =1.6 \cdot 4 \pi \frac{q_{\mathrm{g}}}{\rho_{\mathrm{g}}} N_{\mathrm{i}} r_{\mathrm{i}} \frac{S_{\mathrm{s}}-1}{F_{k}^{\prime}+F_{\mathrm{d}}^{\prime}} \\
\frac{\partial}{\partial t} q_{\mathrm{i}} & =+\operatorname{Sub} I \\
\frac{\partial}{\partial t} q_{\mathrm{v}} & =-\operatorname{Sub} I,
\end{aligned}
$$

where $q_{\mathrm{i}}$ is the specific concentration of cloud ice, $N_{\mathrm{i}}$ is the number of ice crystals per gas volume. The ventilation coefficient for ice crystals is $C_{\mathrm{v}}=1.6$ due to Eq. (11) and the fall velocity is negligible. Contrary to cloud droplets, the ventilation coefficient for ice crystals is larger than 1, since the effective surface of ice crystals is larger than that of a sphere of the same size.

The size distribution for graupel (Eq. (10)) and the ventilation coefficient (Eq. (11)) together with (Eq. (13)) yield after integration over the distribution for deposition and sublimation of graupel:

$$
\begin{aligned}
\operatorname{Sub} H= & 2 \pi \frac{q_{\mathrm{g}}}{\rho_{\mathrm{g}}} N_{0, \mathrm{~h}} \frac{S_{\mathrm{s}}-1}{F_{k}^{\prime}+F_{\mathrm{d}}^{\prime}}\left(1.6 \lambda_{\mathrm{h}}^{-2}\right. \\
& \left.+0.3 \Gamma(2.75) \sqrt{\frac{a_{\mathrm{h}}}{\nu}}\left(\frac{\rho_{0}}{\rho_{\mathrm{g}}}\right)^{1 / 4} \lambda_{\mathrm{h}}^{-2.75}\right) \\
\frac{\partial}{\partial t} q_{\mathrm{h}}= & +\operatorname{Sub} H \\
\frac{\partial}{\partial t} q_{\mathrm{v}} & =-\operatorname{Sub} H .
\end{aligned}
$$

\subsection{Autoconversion}

Larger droplets are formed from cloud droplets by coagulation. This process is called autoconversion and is useful to describe the aggregation of ice crystals to graupel in a similar way. Kessler (1969) suggested a simple approach based on a limited concentration of cloud droplets above which the process starts with a prescribed rate, proportional to the concentration of cloud droplets:

$$
\begin{aligned}
& \text { Aut } C=k_{\mathrm{c}}\left(q_{\mathrm{c}}-\frac{q_{\mathrm{g}}}{\rho_{\mathrm{g}}} a_{\mathrm{c}}\right) \\
& \text { with } k_{\mathrm{c}}=10^{-3} \mathrm{~s}^{-1} \text { and } a_{\mathrm{c}}=5 \cdot 10^{-4} \mathrm{~kg} \mathrm{~m}^{-3} \\
& \frac{\partial}{\partial t} q_{\mathrm{r}}=+\operatorname{Aut} C \\
& \frac{\partial}{\partial t} q_{\mathrm{c}}=-\operatorname{Aut} C .
\end{aligned}
$$


The autoconversion of cloud ice to graupel is temperature-dependent. It occurs only at freezing temperatures and becomes more unlikely the more the temperature decreases (Lin et al., 1983):

$$
\text { Aut } I=k_{\mathrm{i}}\left(q_{\mathrm{i}}-\frac{q_{\mathrm{g}}}{\rho_{\mathrm{g}}} a_{\mathrm{i}}\right)
$$

with $k_{\mathrm{i}}=10^{-3} e^{0.025\left(T-T_{0}\right)} \mathrm{s}^{-1}$ and $a_{\mathrm{i}}=10^{-3} \mathrm{~kg} \mathrm{~m}^{-3}$

$$
\begin{aligned}
& \frac{\partial}{\partial t} q_{\mathrm{h}}=+ \text { Aut } I \\
& \frac{\partial}{\partial t} q_{\mathrm{i}}=- \text { Aut } I .
\end{aligned}
$$

\subsection{Accretion}

Raindrops and graupel can grow by collecting other hydrometeors due to a differential fall velocity. For the accretion of cloud droplets by raindrops, the sedimentation velocity of the former is neglected by definition. A raindrop sweeps out all cloud droplets inside the volume given by its size and fall velocity with a sticking probability $E_{\mathrm{rc}}$. Again, integration over the size distribution of raindrops gives, if $E_{\mathrm{rc}}=1$ :

$$
\begin{aligned}
\operatorname{Acc} R C & =\int_{0}^{\infty} E_{\mathrm{rc}} q_{\mathrm{c}} \pi r^{2} w_{\mathrm{r}}(r) N_{\mathrm{r}}(r) \mathrm{d} r \\
& =\frac{\pi}{4} N_{0, \mathrm{r}} a_{\mathrm{r}} \sqrt{\frac{\rho_{0}}{\rho_{\mathrm{g}}}} \Gamma(3.5) \lambda_{\mathrm{r}}^{-3.5} q_{\mathrm{c}} \\
\frac{\partial}{\partial t} q_{\mathrm{r}} & =+\operatorname{Acc} R C \\
\frac{\partial}{\partial t} q_{\mathrm{c}} & =-\operatorname{Acc} R C .
\end{aligned}
$$

The fall velocity and size distribution of the raindrops correspond to those from Eqs. (7) and (8).

The accretion of ice crystals by graupel is given in an analogous way as:

$$
\text { Acc } H I=\frac{\pi}{4} E_{\mathrm{hi}} N_{0, \mathrm{~h}} a_{\mathrm{h}} \sqrt{\frac{\rho_{0}}{\rho_{\mathrm{g}}}} \Gamma(3.5) \lambda_{\mathrm{h}}^{-3.5} q_{\mathrm{i}}
$$

with $E_{\mathrm{hi}}=e^{0.05\left(T-T_{0}\right)}$

$$
\begin{aligned}
& \frac{\partial}{\partial t} q_{\mathrm{h}}=+\operatorname{Acc} H I \\
& \frac{\partial}{\partial t} q_{\mathrm{i}}=-\operatorname{Acc} H I,
\end{aligned}
$$

with the sticking probability $E_{\mathrm{hi}}$ following Lin et al. (1983).

At temperatures below the freezing point, the graupel's accretion of cloud droplets leads to contact freezing and an increase in the graupel mass. Above the freezing point, the same process causes an energy transfer for the graupel, which in turn drives the melting process described below. Melted graupel and accretioned cloud droplets form new rain water. Similar to Eq. (19), we get with a sticking probability for cloud droplets at graupel $E_{\mathrm{hc}}=1$ :

$$
\begin{aligned}
& \text { Acc } H C=\frac{\pi}{4} N_{0, \mathrm{~h}} a_{\mathrm{h}} \sqrt{\frac{\rho_{0}}{\rho_{\mathrm{g}}}} \Gamma(3.5) \lambda_{\mathrm{h}}^{-3.5} q_{\mathrm{c}} \\
& \frac{\partial}{\partial t} q_{\mathrm{c}}=-\operatorname{Acc} H C \\
& \frac{\partial}{\partial t} q_{\mathrm{h}}=+\operatorname{Acc} H C \text { for } T<T_{0} \\
& \frac{\partial}{\partial t} q_{\mathrm{r}}=+\operatorname{Acc} H C \text { for } T>T_{0} .
\end{aligned}
$$

The accretion of cloud ice by rain leads to contact freezing of supercooled rain water. Graupel is formed by this process, which diminishes both cloud ice as well as rain mass. The change in ice mass can be calculated by an expression similar to Eq. (18). Considering that each ice crystal can freeze no more than one raindrop, the rain water's mass change can be written as:

$$
\begin{aligned}
\operatorname{Acc} R I_{\mathrm{i}} & =\frac{\pi}{4} N_{0, \mathrm{r}} a_{\mathrm{r}} \sqrt{\frac{\rho_{0}}{\rho_{\mathrm{g}}}} \Gamma(3.5) \lambda_{\mathrm{r}}^{-3.5} q_{\mathrm{i}} \\
\operatorname{Acc} R I_{\mathrm{r}} & =q_{\mathrm{r}} \operatorname{Min}\left(\frac{1}{N_{\mathrm{r}}} \frac{\partial}{\partial t} N_{\mathrm{i}}, 1\right) \\
& =q_{\mathrm{r}} \operatorname{Min}\left(\frac{2 \lambda_{\mathrm{r}}}{N_{0, \mathrm{r}}} \frac{3}{4 \pi r_{\mathrm{c}}^{3}} \operatorname{Acc} R I_{\mathrm{i}}, 1\right)
\end{aligned}
$$


$\frac{\partial}{\partial t} q_{\mathrm{h}}=+\operatorname{Acc} R I_{\mathrm{i}}+\operatorname{Acc} R I_{\mathrm{r}}$

$\frac{\partial}{\partial t} q_{\mathrm{i}}=-\mathrm{Acc} I_{\mathrm{i}}$

$\frac{\partial}{\partial t} q_{\mathrm{r}}=-\operatorname{Acc} R I_{\mathrm{r}}$

Finally, a differential fall velocity between graupel and rain also results in accretion. This leads to more graupel below the freezing temperature. Above the freezing temperature, melting graupel leads to the formation of rain. Since graupel and rain have similar fall velocities and size distributions, a double integral has to be solved in order to find an equation for the accretion:

$$
\begin{aligned}
\operatorname{Acc} H R= & \int_{0}^{\infty} \int_{0}^{\infty} E_{\mathrm{rh}} \frac{4}{3} \pi^{2} r_{\mathrm{r}}^{3} \rho_{\mathrm{w}} \frac{q_{\mathrm{g}}}{\rho_{\mathrm{g}}}\left(r_{\mathrm{r}}+r_{\mathrm{h}}\right)^{2} \mid w_{\mathrm{r}}\left(r_{\mathrm{r}}\right) \\
& -w_{\mathrm{h}}\left(r_{\mathrm{h}}\right) \mid N_{\mathrm{h}}\left(r_{\mathrm{h}}\right) \mathrm{d} r_{\mathrm{h}} N_{\mathrm{r}}\left(r_{\mathrm{r}}\right) \mathrm{d} r_{\mathrm{r} .}
\end{aligned}
$$

The double integral can be solved analytically with the assumption that the difference between the fall velocities is given on average by the velocities computed for the mass weighted radii of graupel and rain. Then the difference of the fall velocities can be drawn out of the integral, and, with $E_{\mathrm{rh}}=1$ one obtains:

$$
\begin{aligned}
& \operatorname{Acc} H R=\pi^{2} \rho_{\mathrm{w}} \frac{q_{\mathrm{g}}}{\rho_{\mathrm{g}}} N_{0, \mathrm{r}} N_{0, \mathrm{~h}} \mid w_{\mathrm{r}}\left(\overline{r_{\mathrm{r}}}\right) \\
& \quad-w_{\mathrm{h}}\left(\overline{r_{\mathrm{h}}}\right) \mid\left(\frac{5}{\lambda_{\mathrm{r}}^{6} \lambda_{\mathrm{h}}}+\frac{2}{\lambda_{\mathrm{r}}^{5} \lambda_{\mathrm{h}}^{2}}+\frac{0.5}{\lambda_{\mathrm{r}}^{4} \lambda_{\mathrm{h}}^{3}}\right) \\
& \frac{\partial}{\partial t} q_{\mathrm{h}}=+ \text { Acc } H R \text { for } T<T_{0} \\
& \frac{\partial}{\partial t} q_{\mathrm{r}}=-\operatorname{Acc} H R \text { for } T<T_{0} .
\end{aligned}
$$

\subsection{Melting and freezing}

We suppose that cloud ice will melt instantaneously within one time step and form cloud droplets if it is brought to areas with temperatures exceeding the freezing point:

$\operatorname{Mel} I=\frac{q_{\mathrm{i}}}{\Delta t}$

$\frac{\partial}{\partial t} q_{\mathrm{c}}=+\operatorname{Mel} I$

$\frac{\partial}{\partial t} q_{\mathrm{i}}=-\operatorname{Mel} I$.

Graupel melting is achieved by heat transfer through heat conduction, water vapour diffusion and accretion of cloud or rain water. Following Wisner et al. (1972), we get:

$$
\begin{aligned}
\text { Mel } H= & \frac{q_{\mathrm{g}}}{\rho_{\mathrm{g}}} N_{0, \mathrm{~h}} \frac{2 \pi}{L_{\mathrm{f}}}\left(K_{\mathrm{a}}\left(T-T_{0}\right)\right. \\
& \left.+L_{\mathrm{v}} D_{\mathrm{v}}\left(q_{\mathrm{v}}-q_{\mathrm{sat}}\right) q_{\mathrm{g}}\right) \\
& \times\left(1.6 \lambda_{\mathrm{h}}^{-2}+0.3 \Gamma(2.75)\right. \\
& \left.\times \sqrt{\frac{a_{\mathrm{h}}}{\nu}}\left(\frac{\rho_{0}}{\rho_{\mathrm{g}}}\right)^{1 / 4} \lambda_{\mathrm{h}}^{-2.75}\right) \\
& -\frac{c_{\mathrm{p}, \mathrm{w}}}{L_{\mathrm{f}}}\left(T-T_{0}\right)(\operatorname{Acc} H C+\text { Acc } H R) \\
\frac{\partial}{\partial t} q_{\mathrm{r}}= & +\operatorname{Mel} H \\
\frac{\partial}{\partial t} q_{\mathrm{h}}= & -\operatorname{Mel} H .
\end{aligned}
$$

where $L_{\mathrm{f}}$ is the melting enthalpy, $c_{\mathrm{p}, \mathrm{w}}$ the specific heat capacity of water. Cloud- and rain water cannot only freeze by contact with ice, but also by statistical freezing of supercooled water. Following Bigg (1953) and Barklie (1959), the freezing probability $P$ of a supercooled droplet with radius $r$ can be written as:

$\ln (1-P)=-\frac{4}{3} \pi r^{3} B^{\prime}\left(e^{A^{\prime}\left(T_{0}-T\right)}-1\right)$

with $A^{\prime}=0.66 \mathrm{~K}^{-1}$ and $B^{\prime}=100 \mathrm{~m}^{-3} \mathrm{~s}^{-1}$. 
Then, for statistical freezing of cloud water we find:

$$
\begin{aligned}
\text { Fre } C & =\left(\frac{4}{3} \pi r^{3}\right)^{2} \rho_{\mathrm{w}} N_{\mathrm{c}} \frac{\rho_{0}}{\rho_{\mathrm{g}}} B^{\prime}\left(e^{A^{\prime}\left(T_{0}-T\right)}-1\right) \\
\frac{\partial}{\partial t} q_{\mathrm{i}} & =+\operatorname{Fre} C \\
\frac{\partial}{\partial t} q_{\mathrm{c}} & =-\operatorname{Fre} C
\end{aligned}
$$

and after integration over the size distribution for the statistical freezing of rain water:

$$
\begin{aligned}
\text { Fre } R & =20 \pi^{2} \rho_{\mathrm{w}} N_{0, \mathrm{r}} \lambda_{\mathrm{r}}^{-7} \frac{\rho_{0}}{\rho_{\mathrm{g}}} B^{\prime}\left(e^{A^{\prime}\left(T_{0}-T\right)}-1\right) \\
\frac{\partial}{\partial t} q_{\mathrm{h}} & =+\operatorname{Fre} R \\
\frac{\partial}{\partial t} q_{\mathrm{r}} & =-\operatorname{Fre} R .
\end{aligned}
$$

\subsection{Thermodynamic effects of phase changes}

All microphysical processes that include water phase changes consume or produce thermal energy. For the processes discussed above, the potential temperature $\Theta$ of a gas particle mixture is changed by:

$$
\begin{aligned}
\frac{\partial}{\partial t} \Theta= & \frac{L_{\mathrm{v}}}{c_{\mathrm{p}}}(\operatorname{Con} N+\operatorname{Con} C+\operatorname{Con} R) \\
& +\frac{L_{\mathrm{s}}}{c_{\mathrm{p}}}(\operatorname{Sub} N+\operatorname{Sub} I+\operatorname{Sub} H) \\
& +\frac{L_{\mathrm{f}}}{c_{\mathrm{p}}}\left[\operatorname{Acc} H C+\operatorname{Acc} R I_{\mathrm{r}}+\operatorname{Acc} H R\left(T<T_{0}\right)\right. \\
& -\operatorname{Mel} I-\operatorname{Mel} H+\operatorname{Fre} C+\operatorname{Fre} R],
\end{aligned}
$$

with respect to $c_{\mathrm{p}}$, the specific heat capacity of the gas particle mixture.

A balance procedure guarantees mass conservation and ensures that the phase transfer of water vapour is confined to the existing super- or undersaturation.

\section{Experiments}

\subsection{General description}

The aim of the numerical simulations presented is to study the single and combined effects of entrainment, ice formation and complete microphysics on plume development. We use the $2 \mathrm{~d}$ version of ATHAM formulated in cylindrical coordinates which gives a much better estimate of the horizontal entrainment rates than $2 \mathrm{~d}$ cartesian coordinates. These mixing rates are of great importance for the plume development due to their impact on the water content and the dilution of the volcanic plume which is initially denser than the surrounding atmosphere.

We use a tropical atmosphere at rest (McClatchey et al., 1972) with a tropopause at $17 \mathrm{~km}$ (Fig. 2) for our environmental conditions. The eruption takes place right at the equator, since the Coriolis force is not applicable for cylindrical coordinates. The volcano has a height of $2.8 \mathrm{~km}$ with the crater at $2 \mathrm{~km}$. The eruption parameters given in Table 1 are typical for a plinian eruption.

The horizontal domain is $200 \mathrm{~km}$ and the vertical domain $50 \mathrm{~km}$. This allows the computation of the plume behaviour without disturbances from the model boundaries for a period of at least $1 \mathrm{~h}$. In order to perform model simulations of the full plume development with restricted computer resources, we use stretched grid with a rather coarse resolution of 100 $\mathrm{m}$ at the model's centre. At the lateral boundaries of our horizontal model domain, the grid resolution is 5 $\mathrm{km}$.

The limited spatial resolution of the grid requires a scaling of the original vent diameter from $60 \mathrm{~m}$ to $300 \mathrm{~m}$. Table 1 shows the realistic conditions and the forcing for the scaled experiments. The scaling of the forcing conserves the fluxes of momentum, thermal energy and mass for particles and water vapour, but requires a dilution of the erupted mixture with dry air. Despite the careful scaling process, the behaviour of the plume simulated with higher spatial resolution and realistic forcing differs from the plume simulated with the coarser grid and scaled forcing, i.e., the results of the latter may not be directly applied to the former. However, for general qualitative investigations the use of the computationally cheaper version of the model is justified. 


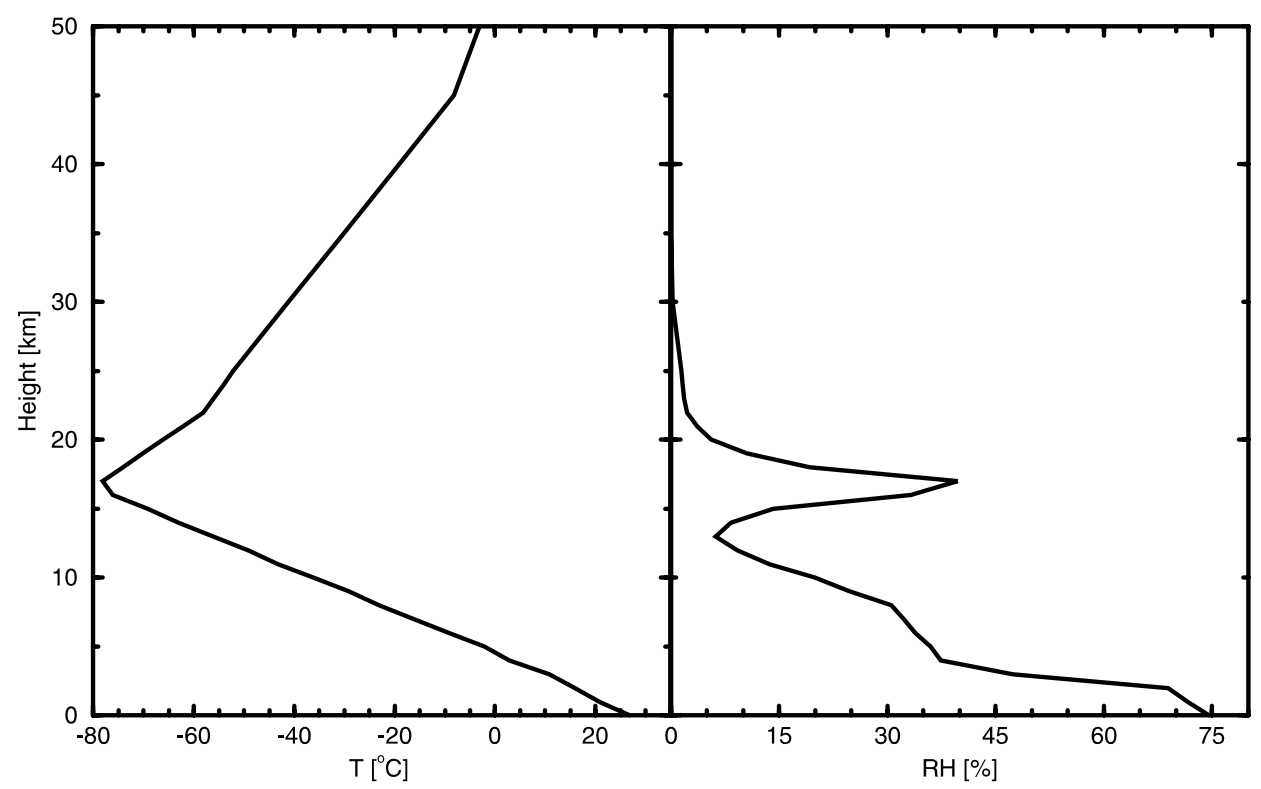

Fig. 2. Meteorological conditions for the experiments (tropical conditions).

To include the effect of silicate particles of different sizes and fall velocities on the plume development, we take into account two types of particles described in Table 2: ash particles have by definition a diameter below $2 \mathrm{~mm}$ (Sparks et al., 1997). In our simulations, we chose a fixed radius of $60 \mu \mathrm{m}$ for ash particles. Lapilli have a diameter between $2 \mathrm{~mm}$ and $64 \mathrm{~mm}$. We use a fixed radius of $2 \mathrm{~mm}$.

The simulated eruptions last for $30 \mathrm{~min}$ : within the first $10 \mathrm{~s}$, the maximum eruption velocity is reached, followed by a $27 \mathrm{~min}$ phase of continuous eruption. During the last $3 \mathrm{~min}$ of eruption, the eruption velocity is returns to zero.

Table 1

Volcanic parameters of the experiment

\begin{tabular}{lll}
\hline Experiment & $\begin{array}{l}\text { Realistic } \\
\text { conditions }\end{array}$ & $\begin{array}{l}\text { Scaled forcing } \\
\text { for the simulations }\end{array}$ \\
\hline$d_{\mathrm{e}}[\mathrm{m}]$ & 60 & 300 \\
$F_{\mathrm{e}}\left[\mathrm{km}^{2}\right]$ & $7.5 \times 7.5$ & $200 \times 50$ \\
$w_{\mathrm{e}}\left[\mathrm{m} \mathrm{s}^{-1}\right]$ & 250 & 131 \\
$T_{\mathrm{e}}[\mathrm{K}]$ & 1200 & 727 \\
$q_{\mathrm{g}, \mathrm{e}}[\mathrm{wt} . \%]$ & 3.0 & 49.1 \\
$\left(q_{\mathrm{v}, \mathrm{e}}\right) /\left(q_{\mathrm{g}, \mathrm{e}}\right)[\%]$ & 66.7 & 2.1 \\
$\rho_{\mathrm{e}}\left[\mathrm{kg} \mathrm{m}^{-3}\right]$ & 5.52 & 0.80 \\
\hline
\end{tabular}

A series of experiments was performed and compared with the simulation including the full microphysics: to study the impact of the microphysics on the plume development, an experiment was performed without microphysics, where all water vapour stayed within the gas phase. The importance of the ice phase was analysed by an experiment which includes only the gaseous and liquid phase of the microphysics. The influence of water vapour entrainment into the plume was investigated by an experiment under dry conditions.

\subsection{Experimental results}

In Fig. 3, the specific concentration of different types of condensed water are shown 25 min after the beginning of the eruption. Cloud water (Fig. 3a) is only formed within the central rising zone $7 \mathrm{~km}$

Table 2

Properties of volcanic products

\begin{tabular}{lcr}
\hline & Ash & Lapilli \\
\hline$\rho\left[\mathrm{kg} \mathrm{m}^{-3}\right]$ & 1500 & 1000 \\
$r[\mathrm{~mm}]$ & 0.06 & 2.00 \\
$\Delta w *\left[\mathrm{~m} \mathrm{~s}^{-1}\right]$ & 0.64 & 7.62 \\
$(P=1 \mathrm{~atm})$ & & \\
\hline
\end{tabular}



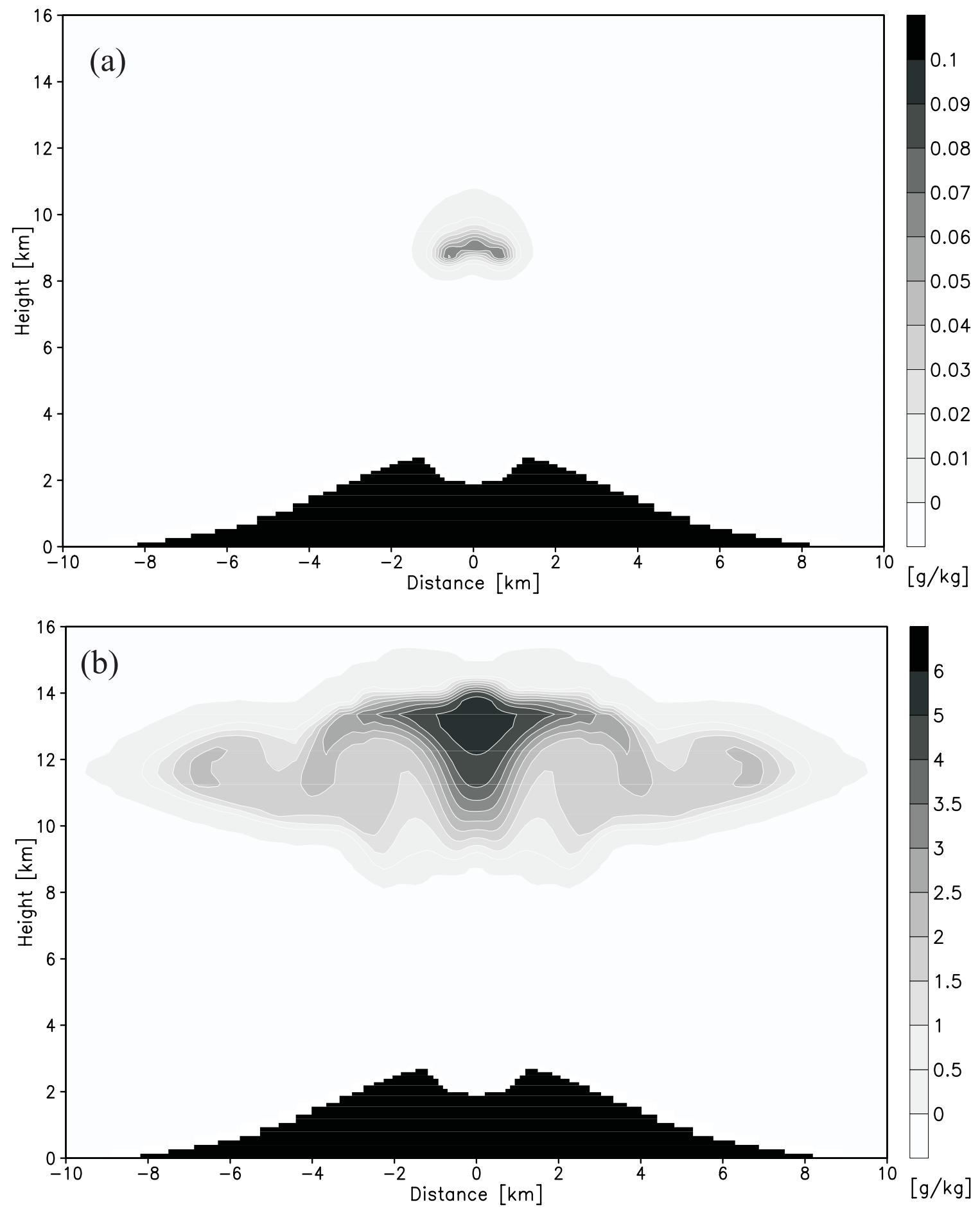

Fig. 3. Concentrations of the different types of condensed water 25 min after the start of the eruption. (a) Cloud water. (b) Cloud ice. (c) Rain. (d) Graupel. 

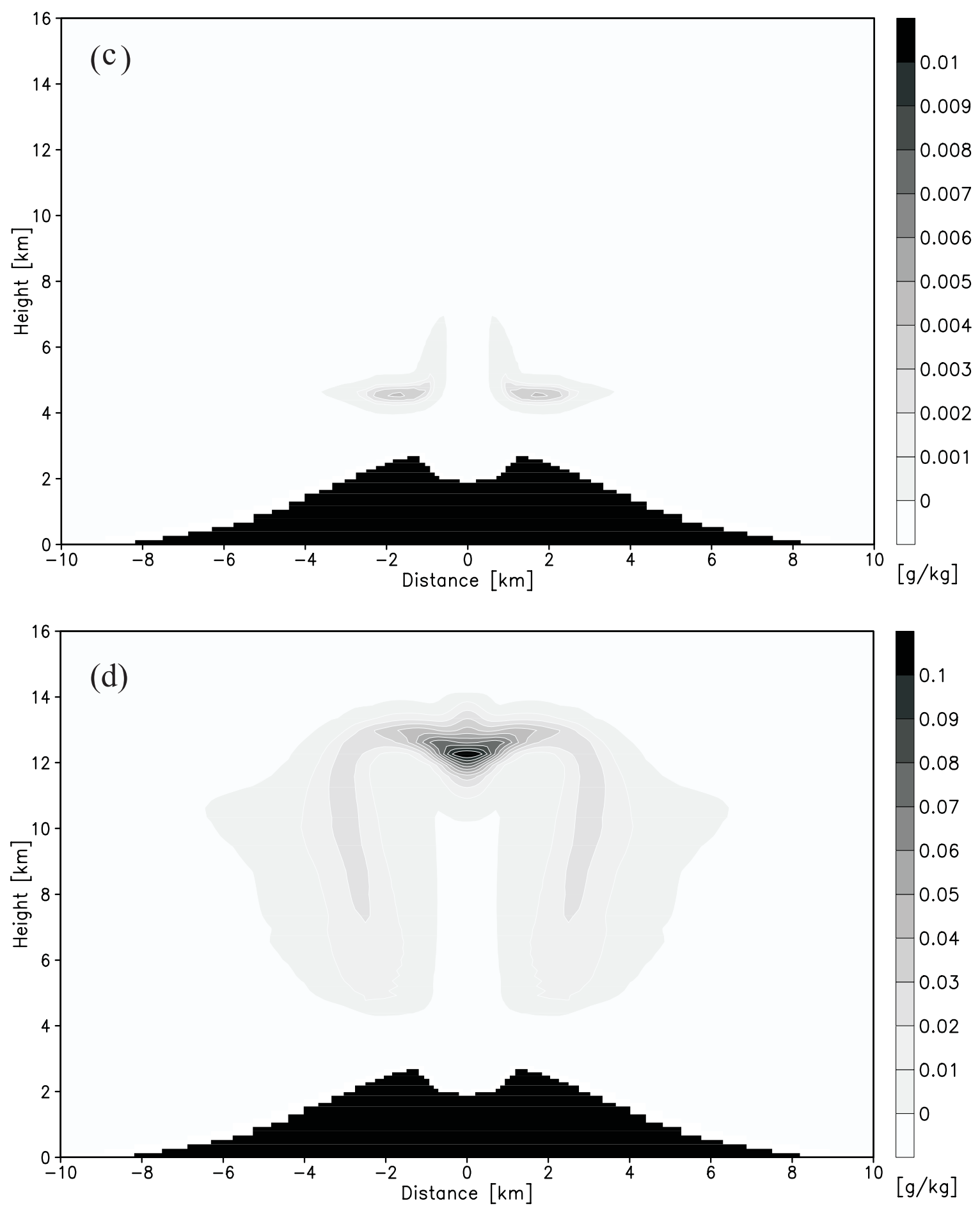

Fig. 3 (continued). 

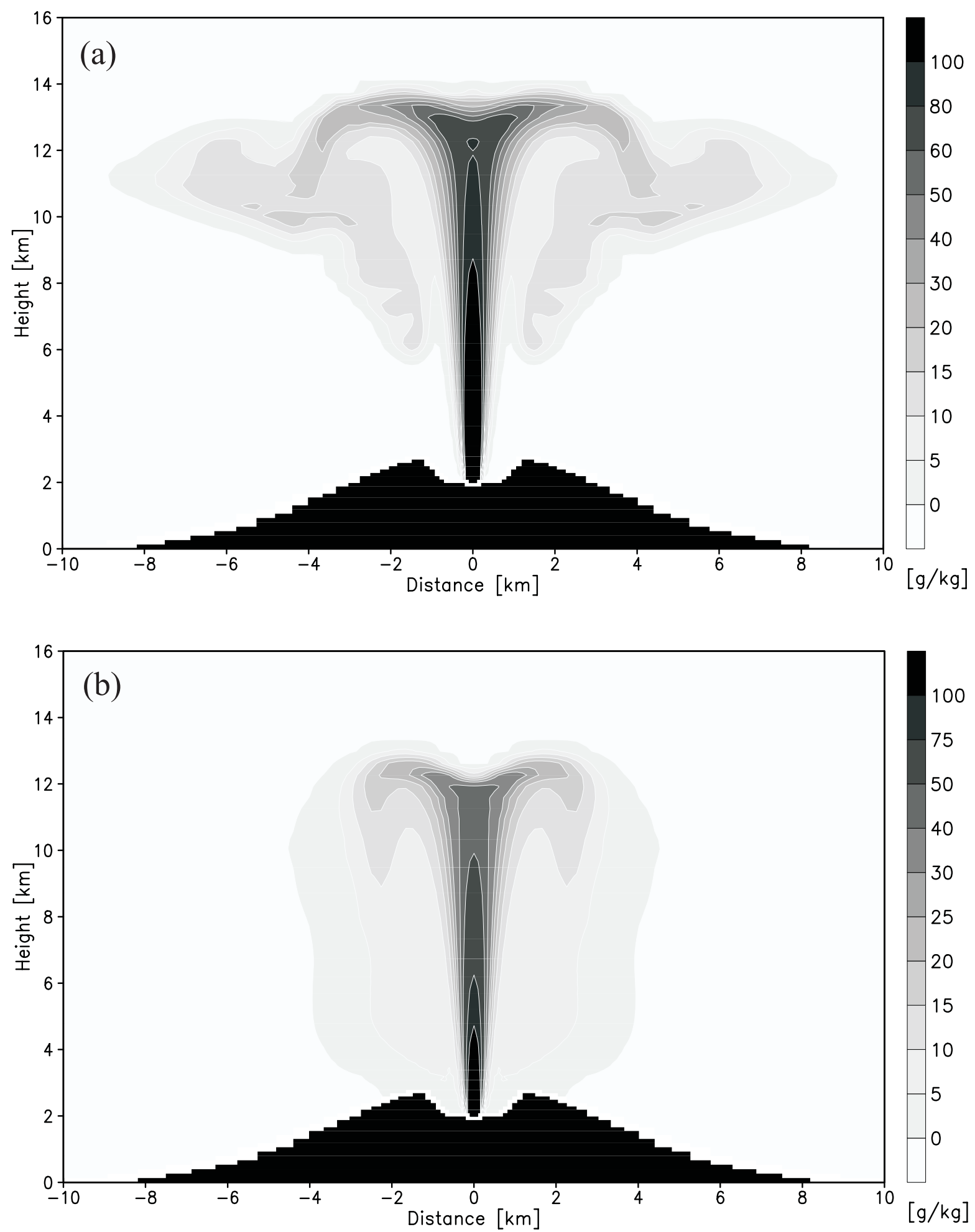

Fig. 4. Concentrations of the different types of volcanic products 25 min after the start of the eruption. (a) Ash. (b) Lapilli. 
above the crater. Since the temperature has just dropped below freezing at this height Fig. 5 only supercooled cloud water exists. Temperatures in the surrounding of the plume below $-25^{\circ} \mathrm{C}$ together with vertical velocities above $60 \mathrm{~m} \mathrm{~s}^{-1}$ lead to rapid freezing of the cloud water.

The most abundant hydrometeor at this time is cloud ice (Fig. 3b). Cloud ice initially results from the freezing of cloud water. Once formed, most of the cloud ice is produced through deposition of water vapour on preexisting cloud ice. Since ice crystals are assumed to be monodisperse, their growing through deposition is not captured by the microphysics. This shortcoming is of minor importance compared with the neglected interaction of hydrometeors and silicate particles. The ice anvil reaches a height of almost $15 \mathrm{~km}$ and therefore does not penetrate the tropical stratosphere. The ice anvil's maximum horizontal extension of $19 \mathrm{~km}$ is reached at a height of $11.5 \mathrm{~km}$.

The formation of graupel through autoconversion of cloud ice is not an effective process because of the temperature dependence of the graupel formation. Low temperatures within the ice anvil below $-35^{\circ} \mathrm{C}$ in most parts of the plume slow down this process. Only small amounts of graupel are formed (Fig. 3d).

Sedimentation and melting of graupel leads the formation of even smaller amounts of rain at lower altitudes (Fig. 3c).

The ash plume (Fig. 4a) is subdivided into three parts. The central rising above the crater reaches a maximum height of $14 \mathrm{~km}$. The umbrella region where the density of the particle gas mixture equals the density of the surrounding atmosphere is formed $3 \mathrm{~km}$ below the maximum plume height, indicating an overshooting of the plume. The upward motion of the rising plume induces a compensational downward motion. As a result of this, small amounts of ash are transported downward eventually reaching the rising plume again, through entrainment.

The difference between ash and ice cloud (Figs. $3 a$ and $4 a$ ) results from the effect of particle gas separation. The mean height of the ash cloud within

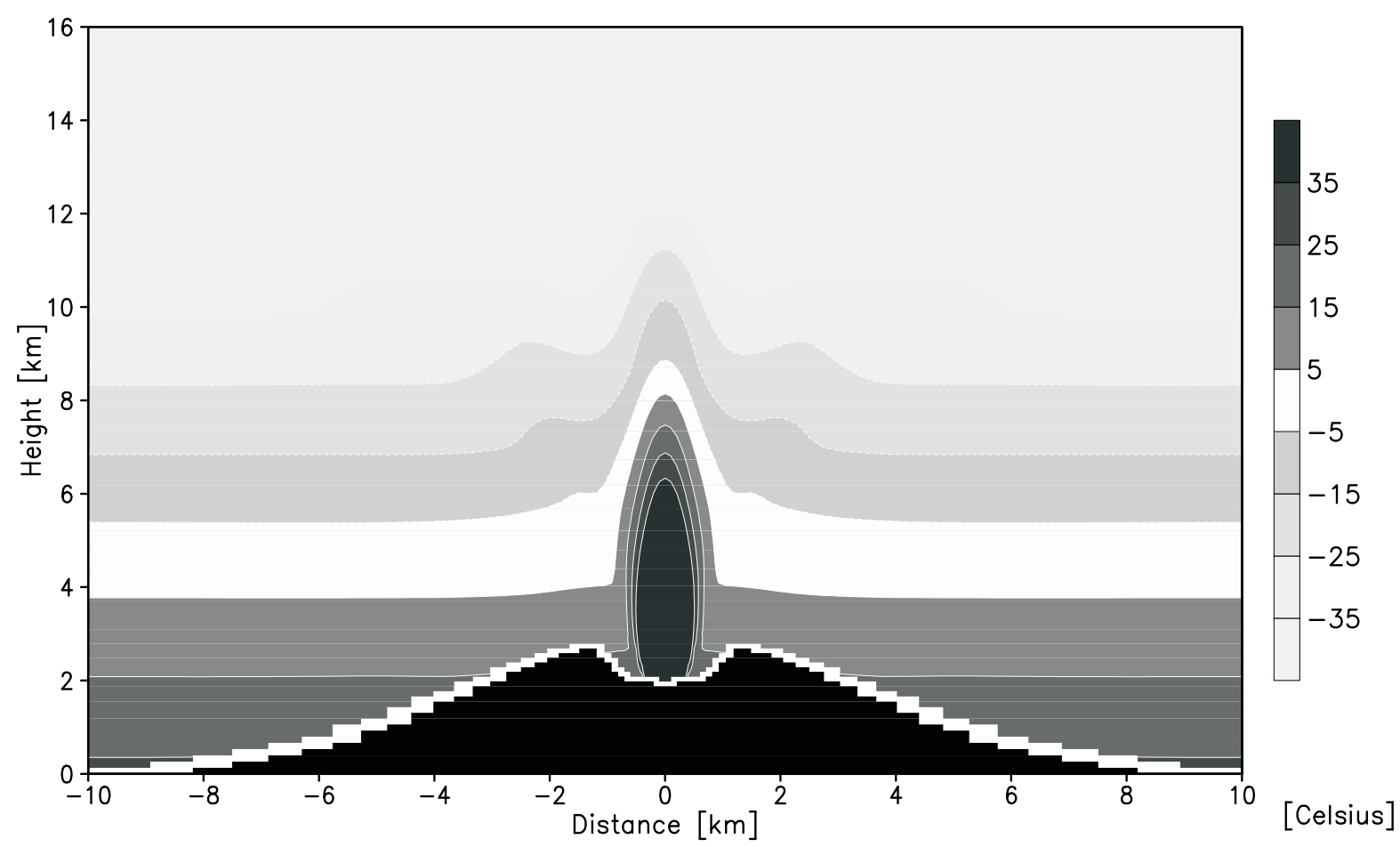

Fig. 5. In situ temperature 25 min after the start of the eruption. 
the umbrella region is only $400 \mathrm{~m}$ lower than that of the ice cloud, which is low compared to the vertical extent of the umbrella region. Hence, for small particles like ash with fall velocities of $2 \mathrm{~m} \mathrm{~s}^{-1}$ in the upper troposphere in our simulations, particle gas separation is only of minor importance $25 \mathrm{~min}$ after the start for the eruption.

This is not true for bigger particles like lapilli (Fig. 4b). Because of sedimentation velocities in the order of $20 \mathrm{~m} \mathrm{~s}^{-1}$ in the upper troposphere, the lapilli rapidly leave the plume's umbrella region. Twenty five minutes after the start of the eruption, $15 \%$ of the erupted lapilli are deposited at the ground.

The ash and lapilli loading dominate the plume's particle density. It is one order of magnitude higher than the particle loading due to hydrometeors.

Fig. 5 shows the in situ temperature and Fig. 6 shows the vertical distribution of both the ash (left panel) and the water anomaly (right panel) $25 \mathrm{~min}$ after the start of the eruption. The water anomaly is the sum of hydrometeors and water vapour anomaly. The water vapour anomaly is the difference between the initialized background values and the simulated water vapour distribution within the plume. The different lines indicate different complexities of the treatment of the microphysics and entrainment. The bold solid curves result from the experiment with the full microphysics already presented in Figs. 3 and 4. The bold dotted curves represent the simulation with water vapour entrainment but without microphysics. The dashed curves result from microphysics computations without considering the ice phase and the dash dotted curves neglect any entrainment of water vapour into the plume. All water originates from the volcanic source.

The effect of microphysical processes leads to a plume which is $1500 \mathrm{~m}$ or $13 \%$ higher than that without phase changes through the microphysics. The maximum ash concentration per meter is reduced by $15 \%$ and the vertical extent of the umbrella region increases, whereas the total mass of the ash plume remains constant (Fig. 6, left panel). Interestingly, the influence of microphysical processes on the plume dynamic does not significantly change the horizontal distribution of ash especially its width, as shown in Fig. 7.

The vertical distribution of water within the plume (Fig. 6, right panel) shows the same increase in

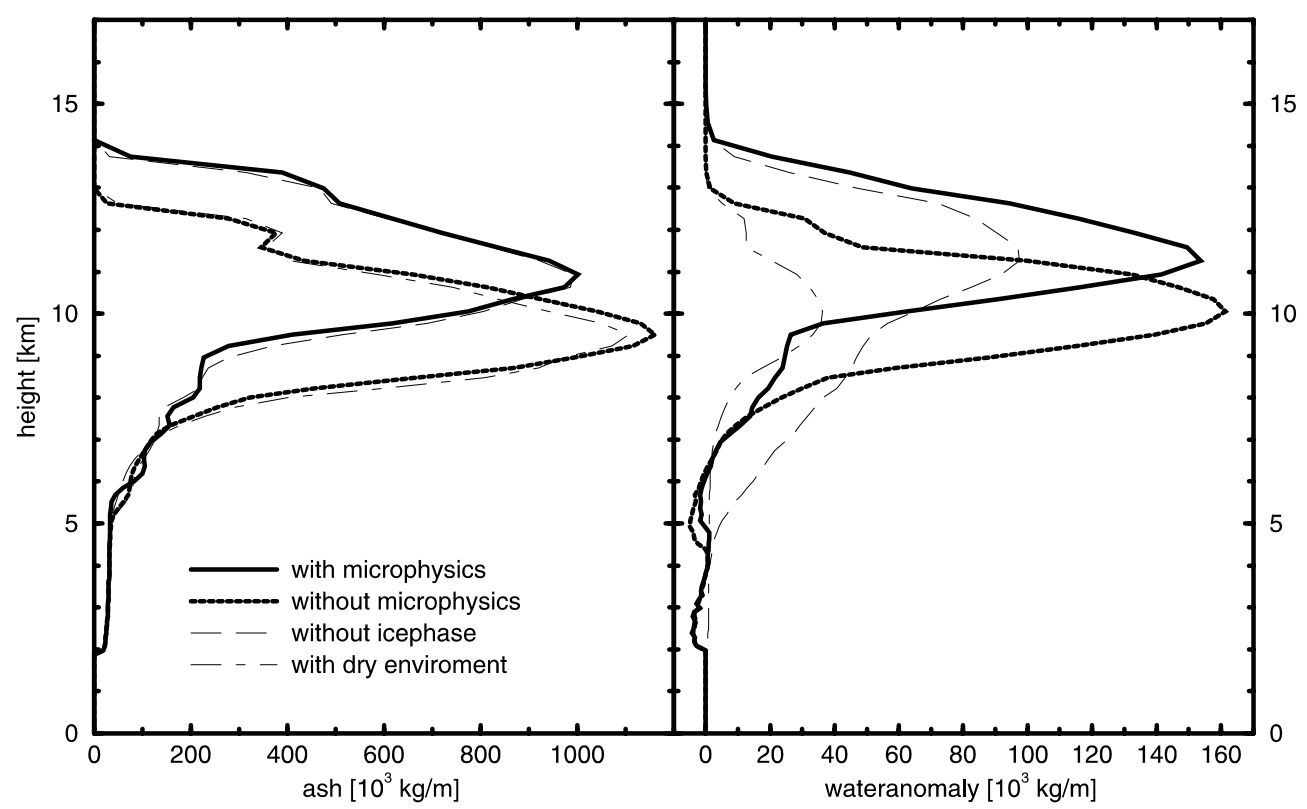

Fig. 6. Vertical distribution of ash and of the anomaly of the total water plume content (all phases) relative to the environment, 25 min after the start of the eruption. 


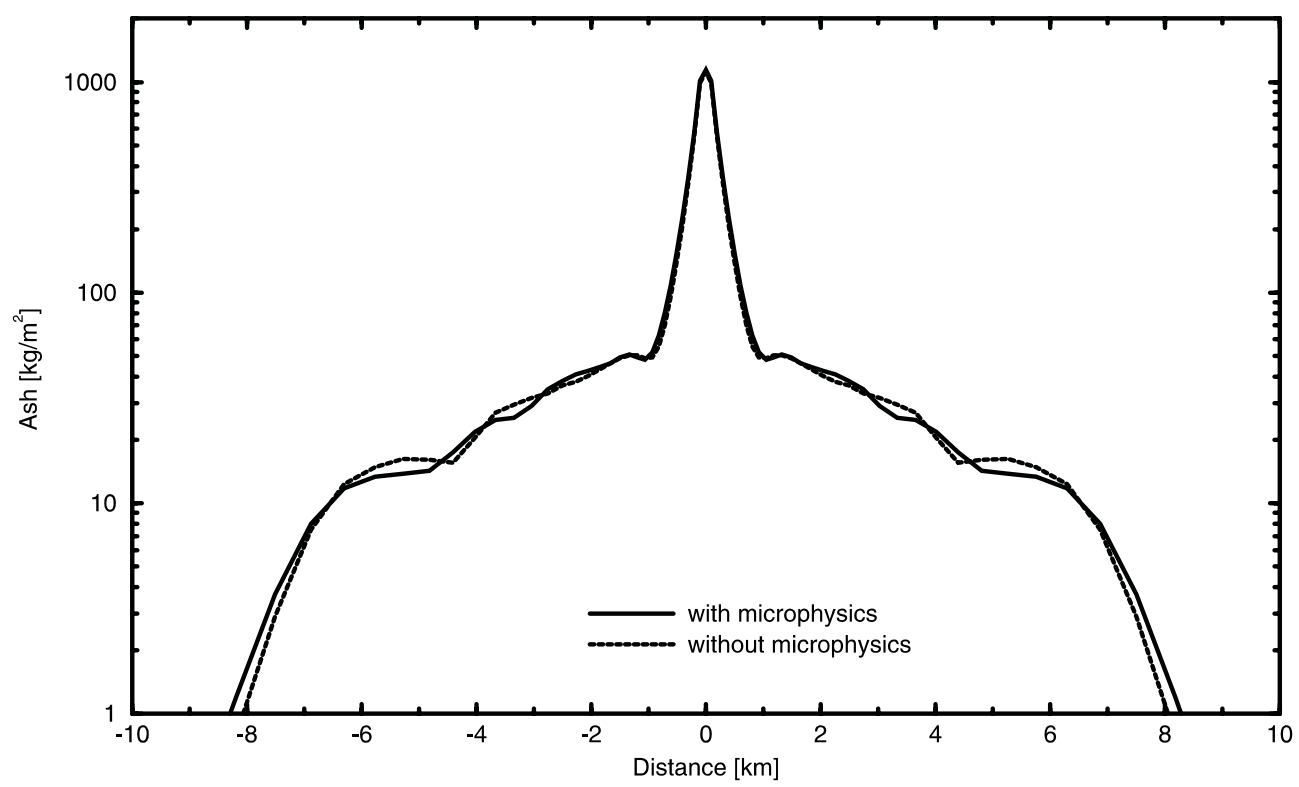

Fig. 7. Horizontal distribution of ash for the experiments with and without consideration of the microphysics, 25 min after the start of the eruption.

height as that of the ash distribution. The effect of particle gas separation is noticeable as already discussed using Figs. 3 and 4. The reduction of the maximum concentration per meter through the influence of microphysical processes is considerably less for water than for ash. This is due to the enhancement of water vapour entrainment into the plume as a consequence of the greater plume rise.

The area confined by the water anomaly curves allows the estimation of the amount of water vapour entrainment into the plume. Negative water anomalies relative to the undisturbed atmosphere above the crater result from the downward transport of relatively dry air at the edges of the plume. This artificial detrainment of water vapour can be corrected by assuming a similar distribution of ash and water in the lower part of the plume. The plume gains about three times more water vapour through entrainment from the surrounding atmosphere than that released from the volcanic source. The amounts of entrained water vapour of the experiments with and without microphysics only differ by $5 \%$.

Microphysical processes within the plume are clearly dominated by the amount of entrained water vapour as confirmed by the experiment with a dry environment: the ash plume only reaches a height which is slightly lower than that in the experiment without microphysics, since the atmospheric stability increases through the neglect of water vapour in the ambient atmosphere. The amount of ice crystals is more than one order of magnitude lower than in a humid environment (Fig. 8, left and right panel). The amount of other hydrometeors is so small that they do not appear in the right panel of Fig. 8. Therefore, the release of latent heat adds less than $1 \%$ to the thermal energy directly released from the volcano, whereas it is $13 \%$ if the entrainment of water vapour from the ambient atmosphere is taken into account.

The experiment without an ice phase can be seen as the extreme case if solution effects are taken into account (Levine, 1995). The real distribution of condensed water in the liquid and solid phase will be between the simulated distributions in the experiments with and without the ice phase. The ash plumes in the experiments with and without the ice phase are almost identical (Fig. 6, left panel). In contrast, the vertical distribution of the water anomaly is significantly changed. The neglect of the ice phase 


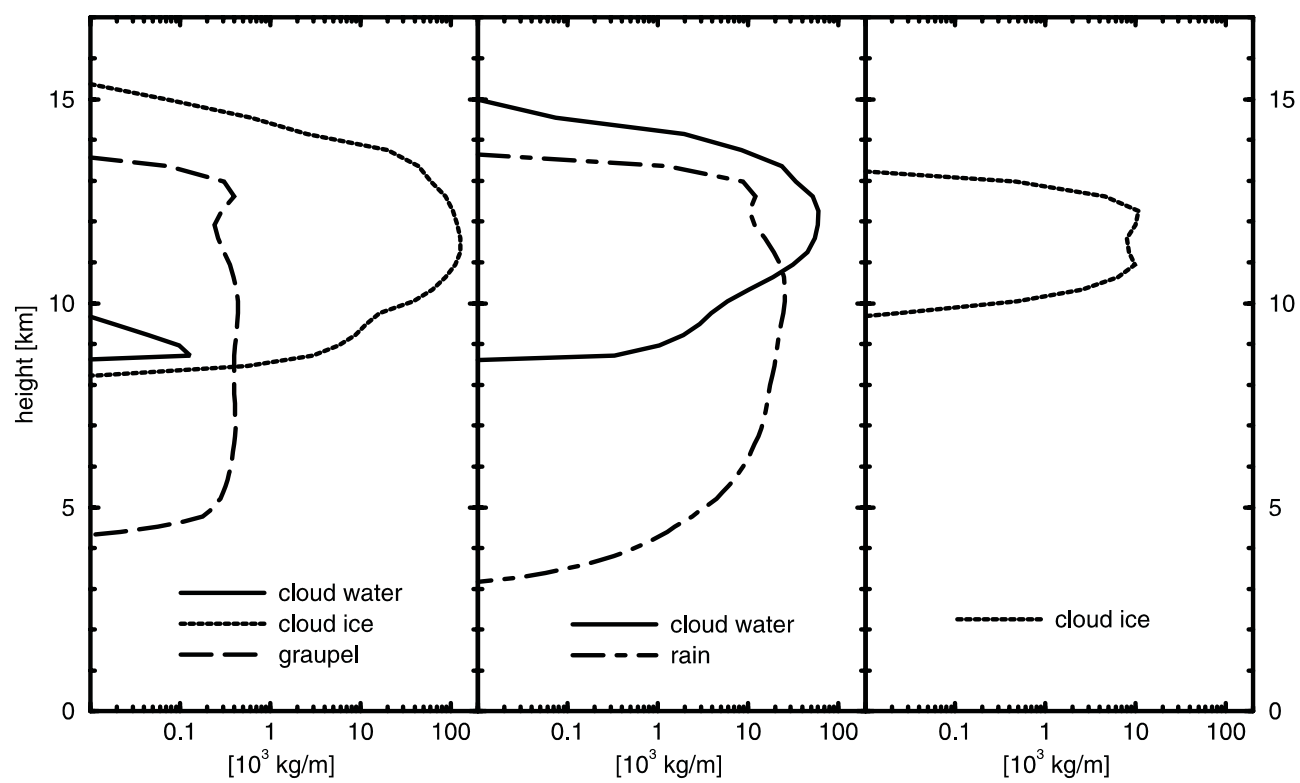

Fig. 8. Vertical distribution of different classes of water for cold cloud (left), warm cloud microphysics (middle) and for the experiment with dry environment (right), $25 \mathrm{~min}$ after the start of the eruption.

leads to an enrichment of cloud water within the umbrella region and to effective rain formation. A lot of water has already left the umbrella region as precipitation as indicated by Fig. 8, middle panel. Twentyfive minutes after the start of the eruption, only half of the condensed water vapour is contained within the umbrella region of the plume. The rain which leaves the plume starts to evaporate. This leads to a cooling and water vapour enrichment of the atmosphere at lower altitudes. The reentrainment of the cooled and water vapour enriched air masses has no net effect on the plume dynamic: the cooling through evaporation is compensated for through the condensation of the additional water vapour and the connected release of latent heat. If we take the ice phase into account, the formation of precipitation is suppressed because of the temperature dependence of the graupel formation. Ninety-nine percent of the condensed water vapour stays as ice crystals within the plume (Fig. 8, left panel).

Although the ice phase's existence is negligible with regards the plume's energy budget, it is of major importance if one takes into account scavenging processes. Volcanic gases can only be dissolved into liquid droplets. Silicate particles may be scav- enged by precipitation. If they are covered with a liquid water skin, they can coagulate and form clusters which leads to an enhanced sedimentation of particles.

\section{Conclusions}

The entrainment of ambient air and water vapour is crucial for the development of a volcanic plume. We formulated a microphysical package that includes the formation of cloud water and ice as well as rain and graupel in a simple bulk approach. This module is applied to the nonhydrostatic volcano plume model ATHAM in order to study the role of entrained water vapour and its microphysical and thermodynamic effects on the plume behaviour. The water phase changes and the transition between the different reservoirs of hydrometeors is treated prognostically, while the fall velocity of the particles is diagnosed at each time step. In order to study more general effects, a simplified $2 \mathrm{~d}$ version of the dynamic code is used which is formulated in cylindrical coordinates. This allows us to study the effect of entrainment in an atmosphere initially at rest. 
The simulation of a volcanic plume in a tropical environment with the full microphysics produces a large amount of water in the ice phase, but relatively little cloud water and rain 25 min after the beginning of the eruption. The release of latent heat adds $13 \%$ to the thermal energy released by the volcano, which leads to a further plume rise of $1500 \mathrm{~m}$. Even if the ice phase is negligible for the energetics of the plume, it cannot be neglected in an investigation of scavenging processes and the formation of precipitation. This is in contrast to earlier studies with simplified one dimensional plume models (Tabazadeh and Turco, 1993; Woods, 1993), since these models only use rough estimates of entrainment rates (Woods, 1988). The entrainment rates do not only determine the amount of water vapour available for microphysical processes but also the temperature distribution by mixing of cooler air from the environment into the plume.

The simultaneous occurrence of ash and hydrometeors indicates that the formation of precipitation should take into account the interaction between hydrometeors and silicate particles. Scavenging processes of volcanic gases and silicate particles and their impact on microphysical processes will be subject of another paper (Textor et al., in preparation). Since the knowledge of microphysical processes within a volcanic eruption plume is very poor, simplified microphysical descriptions as presented here give useful hints about the processes involved.

\section{Acknowledgements}

This study was performed under sponsorship of the Volkswagen-Stiftung, grant EVA (Emission of Volatiles to the Atmosphere).

\section{References}

Barklie, R.H.D., 1959. Nucleation measurements on rain and melted hail. Sci. Rep. MW-30, Stormy Weather Research Group, McGill University.

Bigg, E.K., 1953. The supercooling of water. Proc. Phys. Soc. (London) B66, 688-694.

Byers, H.R., 1965. Elements of Cloud Physics. The University of Chicago Press.

Carey, S., Sparks, R.S.J., 1986. Quantitative models of the fall out and dispersal of tephra from volcanic eruption columns. Bull. Volcanol. 48, 109-125.

Coffey, M.T., 1996. Observations of the impact of volcanic activity on stratospheric chemistry. J. Geophys. Res. 101, 6767-6780.

Federer, B., Waldvogel, A., 1975. Hail and raindrop size distributions from a Swiss multicell storm. J. Appl. Meteorol. 14, 91-97.

Fletcher, N.H., 1962. The Physics of Rainclouds. Cambridge Univ. Press, London.

Glaze, L.S., Baloga, S.M., Wilson, L., 1997. Transport of atmospheric water vapour by volcanic eruption columns. J. Geophys. Res. 102, 6099-6108.

Gunn, R., Kinzer, G.D., 1949. The terminal velocity of fall for water drops in stagnant air. J. Meteorol. 6, 243-248.

Kessler, E., 1969. On the distribution and continuity of water substance in atmospheric circulation. Met. Monographs 10, 84 .

Levine, I.N., 1995. Physical Chemistry, 4th edn. Mc Graw-Hill, New York.

Lin, Y., Farley, R.D., Orville, H.D., 1983. Bulk parameterization of the snow field in a cloud model. J. Climate Appl. Meteorol. 22, 1065-1092.

Linke, F., Baur, F. (Eds.), 1970. Meteorologisches Taschenbuch. Akademische Verlagsgesellschaft, Geest\&Portig.

Loth, B., Graf, H.-F., Oberhuber, J.M., 1993. Snow cover model for global climate simulations. J. Geophys. Res. 98, 1045110464.

Marshall, J.S., Palmer, W.cKM., 1948. The distribution of rain drop size. J. Meteorol. 5, 165-166.

McClatchey, R.A., Fenn, R.W., Selby, J.E.A., Volz, F.E., Garing, J.S., 1972. Optical properties of the atmosphere, 3rd edn. Environmental Research Papers (411).

Murcray, D.G., Murcray, F.J., Barker, D.B., 1981. Changes in stratospheric water vapour associated with the Mount St. Helens eruption. Science 211, 823-824.

Oberhuber, J.M., Herzog, M., Graf, H.-F., Schwanke, K., 1998. Volcanic plume simulation on large scales. J. Volcanol. Geotherm. Res. 87, 29-53.

Rogers, R.R., Yau, M.K., 1989. A Short Course on Cloud Physics, 3rd edn. Pergamon, Oxford.

Rose, W., Delene, D., Schneider, D., Bluth, G., Krueger, A., Sprod, I., McKee, C., Davies, H., Ernst, G., 1995. Ice in the 1994 Rabaul eruption cloud: implications for volcano hazard and atmospheric effects. Nature 375, 477-479.

Rutledge, S.A., Hobbs, P.V., 1983. The mesoscale and microscale structure and organization of clouds and precipitation in midlatitude cyclones: VIII. A model for the 'seeder-feeder' process in warm-frontal rainbands. J. Atmos. Sci. 40, 1185-1206.

Schwanke, K., 1995. Sensitivitätsstudie zur Ausbreitung von vulkanischen Emissionen mit Hilfe eines numerischen Modells, Master's thesis, University at Hamburg.

Sheridan, M.F., Wohletz, K.H., 1983. Origin of accretionary lapilli from the Pompeii and Avellino deposits. In: Gooley, R. (Ed.), Microbeam Analysis, pp. 35-38.

Sparks, R.S.J., Bursik, M.I., Carey, S.N., Gilbert, J.S., Glaze, L.S., Sigurdsson, H., Woods, A.W., 1997. Volcanic Plumes. Wiley, New York. 
Stephens, M.A., 1979. A simple ice phase parameterization, Atmos. Sci. Pap. No. 319. Colorado State University.

Tabazadeh, A., Turco, R.P., 1993. Stratospheric chlorine injection by volcanic eruptions: $\mathrm{HCl}$ scavenging and implications for ozone. Science 260, 1082-1086.

Weast, R.C., Astle, M.J., Beyer, W.H. (Eds.), 1984. Handbook of Chemistry and Physics, 64th edn. CRC Press, Boca Raton, FL.
Wisner, C., Orville, H.D., Myres, C., 1972. A numerical model of a hail-bearing cloud. J. Atmos. Sci. 29, 1160-1181.

Woods, A.W., 1988. The fluid dynamics and thermodynamics of eruption columns. Bull. Volcanol. 50, 169-193.

Woods, A.W., 1993. Moist convection and the injection of volcanic ash into the atmosphere. J. Geophys. Res. 98, 1762717636. 